\title{
PHYSICAL AND MATHEMATICAL MODELS OF BAKING PROCESS OF DOUGH PIECES IN OVEN UNITS
}

\author{
A. Kovalyov, V. Shutyuk
}

National University of Food Technologies

A. Karwacki

National Technical University of Ukraine “ Kyiv Polytechnic Institute»

\begin{tabular}{l}
\multicolumn{1}{c}{ Key words: } \\
Modelling \\
Baking \\
Heat and mass transfer \\
Dough piece \\
\hline \multicolumn{1}{c}{ Article history: } \\
Received 11.01.2018 \\
Received in revised form \\
25.01.2018 \\
Accepted 06.02.2018 \\
\hline
\end{tabular}

Corresponding author:

V. Shutyuk

E-mail:

schutyuk@i.ua

\begin{abstract}
Bread baking is the most important industrial process of bakery goods production. The oven unit is the key equipment for a bread factory, the main function of which is production of high-quality goods maintaining the high technical and economic output values at minimal energy expenditure. In order to ensure qualitative characteristics of the oven it is vital to use the models of a real-world system and conduct experiments for analysis, engineering or re-engineering, control and predicting a particular real process.

The given article focuses on the physical and mathematical models of the baking process of dough pieces in oven units as exemplified by the industrial oven with a chain conveyor K-PXM-25. The mathematical model of bread baking process in the gas ducts of a baking chamber was developed, which takes into account radiation and convection heat transfer, mass transfer along with moisture vapor infusion ensuring dough pieces dampening and multiphase flow turbulence. The gas channel medium of the bakery oven is considered to be biphasic, selective, radiating, and absorbent, being surrounded by diffusive boundaries and consisting of heating gases and vapor, which is used to moisturize the dough pieces. Dough billets and bread are treated as damp capillary-porous media with effective physical properties. The relation of the multiphase flow is formulated on the basis of the data of the Eulerian equation system averaged according to Reynolds.

The model for dough piece baking developed by the authors allows take into account technological modes and construction features of the modern conveyor oven units as well as conduct grounded performance research of the joint heat exchange in them resulting in the high quality of the end bakery product with sufficient precision and detail.
\end{abstract}

DOI: $10.24263 / 2225-2924-2018-24-1-19$ 


\title{
ФІЗИЧНА I МАТЕМАТИЧНА МОДЕЛЬ ПРОЦЕСУ ВИПІКАННЯ ТІСТОВИХ ЗАГОТОВОК У ХЛІБОПЕКАРСЬКИХ ПЕЧАХ
}

\author{
О.В. Ковальов, В.В. Шутюк
}

Національний університет харчових технологій

\section{А.Я. Карвацький}

Начіональний технічний університет Украӥни «Київський політехнічний інститут»

Випікання хліба - найважливіший прочес у виробництві хлібобулочних виробів. Хлібопекарська піч - основне обладнання хлібозаводу, призначенням якого є вироблення високоякісної продукиії при забезпеченні високих технікоекономічних показників виходу продукиії при мінімальних витратах енергоресурсів. Для забезпечення якісних показників роботи печі необхідно використовувати моделі реальної системи та проводити експерименти для аналізу, проектування або перепроектування, контролю у прогнозування певного реального прочесу.

У статті наведено фізичну й математичну модель процесу випікання тістових заготовок у хлібопекарських печах на прикладі промислової печі з колисковим конвеєром К-ПХМ-25. Розроблено математичну модель прочесу випікання хліба в газових каналах пекарної камери з урахуванням радіаційноконвективного теплообміну, масообміну з урахуванням введення водяної пари для зволожування тістових заготовок $i$ турбулентності багатофазного потоку. Середовище газових каналів хлібопекарської печі вважається двофазним, селективним випромінювальним і поглинальним, оточене дифузними гранииями й складається з грійних газів і водяної пари, щьо використовується для зволоження тістових заготовок. Тістові заготовки та хліб вважаються вологим капілярно-пористим середовищем з ефективними фізичними властивостями. Залежність турбулентності багатофазного потоку сформульована на основі осереднених за Рейнольдсом системи рівнянь Ейлера.

Розроблена авторами модель випікання тістових заготовок дає змогу з достатньою точністю і детальністю враховувати технологічні режими та конструктивні особливості сучасних конвеєрних хлібопекарських печей $i$ проводити широкі параметричні дослідження сполученого теплообміну в них з виходом на кінцевий показник - якість готових хлібобулочних виробів.

Ключові слова: моделювання, випікання тепломасоперенесення, тістова заготовка.

Постановка проблеми. Випікання хліба - найважливіший процес у виробництві хлібобулочних виробів. Смак, аромат, пористість, глянець та інші показники якості готових виробів $є$ наслідком ряду фізико-хімічних змін всередині продукту під час випікання, які залежать передусім від теплового режиму випікання і парозволоження $[1-3]$. 
Піч $є$ основним обладнанням хлібозаводу, вона визначає тип і потужність підприємства, асортимент і якість продукції. Піч - не лише тепловий, але насамперед технологічний агрегат, основним призначенням якого $\epsilon$ вироблення високоякісної продукції при забезпеченні високих техніко-економічних показників виходу продукції при мінімальних витратах енергоресурсів. Для забезпечення якісних показників роботи печі необхідно використовувати моделі реальної системи та проводити експерименти на основі математичної моделі для аналізу, проектування або перепроектування, контролю та прогнозування певного реального процесу.

Аналіз останніх досліджень і публікацій. Дослідники завжди прагнули отримати точну математичну модель для моделювання хлібопечення. Так, M. Lostie та ін. [4] розробили модель процес випікання дріжджового тіста й оцінки впливу технологічних параметрів. B. Broyart i G.Trystram [5] проаналізували тепломасоперенесення та зміни якості продукції при безперервному випіканні печива на основі моделювання індуктивних печей. J. Bikard та ін. [6] розробили модель випікання хліба, використовуючи прямий $3 \mathrm{D}-$-исловий метод у мікромасштабі на основі аналізу поля теплових потоків при випікання. N. Baldino та ін. [7] отримали математичну залежність процесу випікання бісквіту. М.Г. Десик та ін. [8] описали залежність прогріву тістової заготовки циліндричної форми.

У пропонованій статті ми представляємо фізичну та математичну моделі, призначені для опису тепломасоперенесення всередині пористого матеріалу під час випікання.

Мета статті: розробити математичну модель процесу випікання хліба в газових каналах пекарної камери 3 урахуванням радіаційно-конвективного теплообміну, масообміну з урахуванням введення водяної пари для зволожування тістових заготовок і турбулентності багатофазного потоку.

\section{Викладення основних результатів дослідження.}

Фізична модель.

Конструкція хлібопекарської печі К-ПХМ-25 (рис. 1) включає такі компоненти: суцільнометалеву конструкцію, зібрану з окремих модулів і теплоізольовану зовні мінеральною ватою, газові канали, в яких відбувається випічка хліба, рухомий колисковий конвеєр для переміщення тістових заготовок (Т3) у газових каналах, вхідних і вихідних вузлів печі, що включають газохід для підводу грійних газів, систему парозволоження, завантажувальнорозвантажувальний пристрій. Тобто в розглянутій фізичній моделі хлібопекарської печі топково-запальниковий блок не розглядається та, відповідно до цього, процеси горіння палива також.

Середовище газових каналів хлібопекарської печі вважається двофазним, селективним випромінювальним та поглинальним, оточене дифузними границями і складається з грійних газів та водяної пари, що використовується для зволоження тістових заготовок.

Тістові заготовки та хліб вважаються вологим капілярно-поруватим середовищем з ефективними фізичними властивостями. Тістові заготовки переміщуються разом із колисковим конвеєром. 


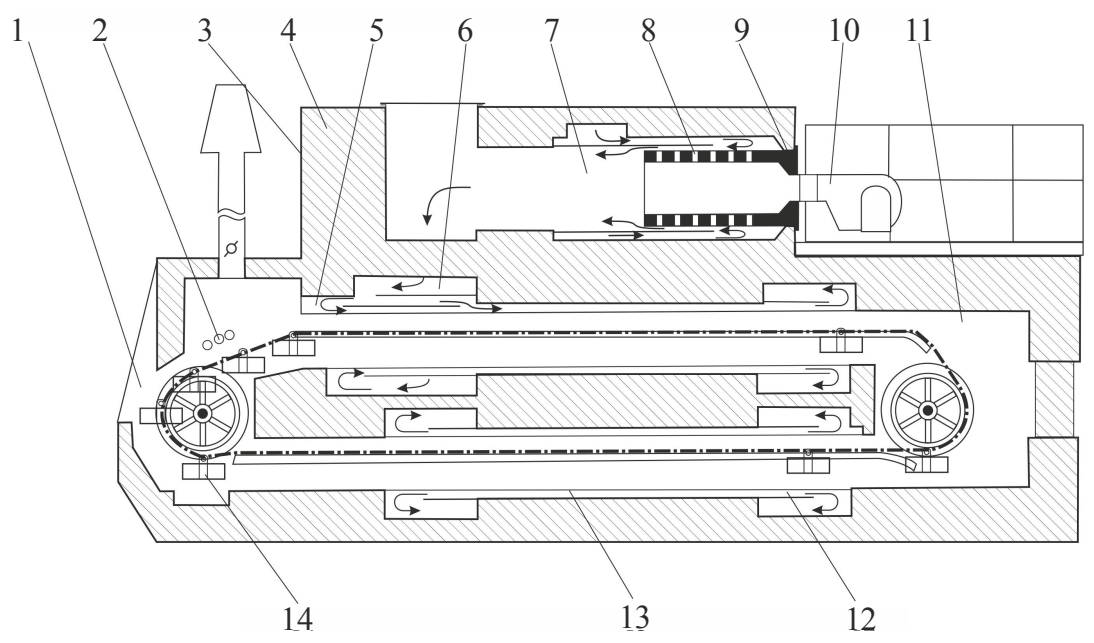

Рис. 1. Хлібопекарська піч К-ПХМ-25

1 - завантажувально-розвантажувальний пристрій; 2 - система парозволоження; 3 - суцільнометалева конструкція; 4 - теплоізоляція; 5, 13 - верхні і нижні нагрівальні канали; 6, 12 - верхні і нижні газоходи; 7 - топка; 8 - камера змішування; 9 - муфель; 10 - пальник; 11 - пекарна камера; 14 - колисковий конвеєр

\section{Математична модель.}

Математичну модель процесу випічки хліба в газових каналах пекарної камери печі з урахуванням радіаційно-конвективного теплообміну, масообміну за рахунок введення водяної пари (з краплями води) для зволожування тістових заготовок, що випікаються, турбулентності багатофазного потоку можна сформулювати за допомогою осереднених за Рейнольдсом системи рівнянь Ейлера $[9 ; 10]$ (записаних для кожної з фаз): нерозривності, збереження кількості руху, кінетичної турбулентної енергії та іiі дисипації і збереження енергіi:

$$
\frac{1}{\rho_{r i}}\left\{\left[\frac{\partial\left(\alpha_{i} \rho_{i}\right)}{\partial \tau}+\nabla \cdot\left(\alpha_{i} \rho_{i} \bar{V}_{i}\right)\right]=\sum_{j=1}^{n}\left(\dot{m}_{j i}-\dot{m}_{i j}\right)\right\},
$$

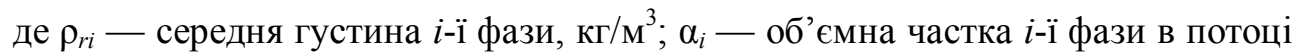

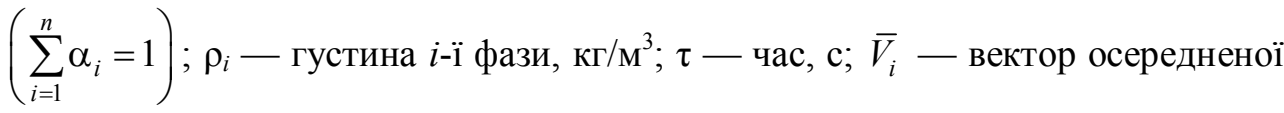
за Рейнольдсом або за Фавром швидкості $i$-ї фази, м/с; $\nabla-$ оператор Гамільтона, $\mathrm{M}^{-1} ; \dot{m}_{j i}$ і $\dot{m}_{i j}$ - швидкість передачі маси від фази $j$ до фази $i \mathrm{i}$, навпаки, відповідно (причому $\left.\dot{m}_{i i}=0\right)$, кг/(c· $\left.\mathrm{M}^{3}\right) ; n-$ кількість фаз у потоці.

$$
\begin{aligned}
& \frac{\partial\left(\alpha_{i} \rho_{i} \bar{V}_{i}\right)}{\partial \tau}+\left(\alpha_{i} \rho_{i} \bar{V}_{i} \cdot \nabla\right) \bar{V}_{i}=-\alpha_{i} \nabla p_{i}+\nabla \cdot \tau_{i}+\alpha_{i} \rho_{i} g+ \\
& +\sum_{j=1}^{n}\left[K_{j i}\left(\bar{V}_{j}-\bar{V}_{i}\right)+\dot{m}_{j i} \bar{V}_{j i}-\dot{m}_{i j} \bar{V}_{i j}\right]+F_{i}+F_{l i f t, i}+F_{v m, i},
\end{aligned}
$$


де $p_{i}$ - парціальний тиск $i-\ddot{i}$ фази, Па; $\mu_{i}$ i $\lambda_{i}$ - зсувна і об'ємна в'язкість фази $i$, відповідно, Па.с; $\tau_{i}=\alpha_{i} \mu_{i}\left[\nabla \bar{V}_{i}+\nabla \bar{V}_{i}^{T}\right]+\alpha_{i}\left(\lambda_{i}-\frac{2}{3} \mu_{i}\right) \nabla \cdot \bar{V}_{i} I-$ тензор напружень 2-го рангу (або фізичне рівняння стану середовища, що зв'язує напруження зі швидкістю деформації), Па; I - одиничний тензор 2-го рангу; $\mathrm{g}$ - вектор прискорення, пов'язаний з гравітацією, м $/ \mathrm{c}^{2} ; K_{j i}=K_{i j}-$ коефіцієнт обміну кількістю руху між фазами, що залежить від тертя, тиску та інших факторів, кг/(м $\left.{ }^{3} \cdot \mathrm{c}\right) ; \bar{V}_{j i}\left(\bar{V}_{j}\right.$ при $\dot{m}_{j i}>0, \bar{V}_{i}$ при $\left.\dot{m}_{j i}<0\right)$ - швидкість руху міжфазної поверхні, м/с; $F_{i}$ — зовнішня масова сила, віднесена до об'єму, Н/м³ ; $F_{\text {lift }, i}=-0,5 \rho_{g} \alpha_{p}\left(\bar{V}_{g}-\bar{V}_{p}\right) \cdot\left(\nabla \cdot \bar{V}_{g}\right)$ - підйомна об'ємна сила, Н/м³; $g$ індекс грійних газів; $p$ - індекс водяної пари з включенням крапель води; $F_{v m, i}=0,5 \alpha_{p} \rho_{s}\left(d \bar{V}_{g} / d \tau-d \bar{V}_{p} / d \tau\right)$ - приєднана об'ємна сила, Н/м³;

$$
\begin{gathered}
\frac{\partial\left(\alpha_{i} \rho_{i} k_{i}\right)}{\partial \tau}+\nabla \cdot\left(\alpha_{i} \rho_{i} \bar{V}_{i} k_{i}\right)=\nabla \cdot\left[\alpha_{i}\left(\mu_{i}+\frac{\mu_{t, i}}{\sigma_{k}}\right) \nabla k_{i}\right]+\left(\alpha_{i} G_{k, i}-\alpha_{i} \rho_{i} \varepsilon_{i}\right)+ \\
\quad+\sum_{j=1}^{n} K_{j i}\left(C_{j i} k_{j}-C_{i j} k_{i}\right)-\sum_{j=1}^{n} K_{j i}\left(\bar{V}_{j}-\bar{V}_{i}\right)\left(\frac{\mu_{t, j}}{\alpha_{j} \sigma_{k}} \nabla \alpha_{j}-\frac{\mu_{t, i}}{\alpha_{i} \sigma_{k}} \nabla \alpha_{i}\right), \\
\frac{\partial\left(\alpha_{i} \rho_{i} \varepsilon_{i}\right)}{\partial \tau}+\nabla \cdot\left(\alpha_{i} \rho_{i} \bar{V}_{i} \varepsilon_{i}\right)=\nabla \cdot\left(\alpha_{i} \frac{\mu_{t, i}}{\sigma_{\varepsilon}} \nabla \varepsilon_{i}\right)+\frac{\varepsilon_{i}}{k_{i}}\left(C_{1 \varepsilon} \alpha_{i} G_{k, i}-C_{2 \varepsilon} \alpha_{i} \rho_{i} \varepsilon_{i}\right)+ \\
+C_{3 \varepsilon} \frac{\varepsilon_{i}}{k_{i}}\left[\sum_{j=1}^{n} K_{j i}\left(C_{j i} k_{i}-C_{i j} k_{i}\right)-\sum_{j=1}^{n} K_{j i}\left(\bar{V}_{j}-\bar{V}_{i}\right)\left(\frac{\mu_{t, j}}{\alpha_{j} \sigma_{\varepsilon}} \nabla \alpha_{j}-\frac{\mu_{t, i}}{\alpha_{i} \sigma_{\varepsilon}} \nabla \alpha_{i}\right),\right.
\end{gathered}
$$

де $k_{i}$ - масова турбулентна кінетична енергія $i$-ї фази, Дж/кг; $\mu_{t, i}=\rho_{i} C_{\mu} k_{i}^{2} / \varepsilon_{i}-$ турбулентна в'язкість $i$-ї фази, Па·с; $\varepsilon_{i}$ - швидкість дисипації турбулентної кінетичної енергії $i$-ї фази, Дж/(кг·с); $G_{k, i}=\mu_{t, i} \nabla \bar{V}_{i}\left(\nabla \bar{V}_{i}+\bar{V}_{i} \nabla\right), \Pi$ Па/c; $C_{j i}=2$, $C_{i j}=2 \eta_{j i} /\left(1+\eta_{j}\right)$ - коефіцієнт, зв'язаний з дисперсією крапель [2]; $\sigma_{k}-$ константа; $\sigma_{k}, \sigma_{\varepsilon}, C_{\mu}, C_{1 \varepsilon}, C_{2 \varepsilon}, C_{3 \varepsilon},-$ параметри (константи) $k-\varepsilon$ моделі;

$$
\begin{gathered}
\frac{\partial\left(\alpha_{i} \rho_{i} h_{i}\right)}{\partial \tau}+\nabla \cdot\left(\alpha_{i} \rho_{i} \bar{V}_{i} h_{i}\right)=\alpha_{i} \frac{\partial p_{i}}{\partial \tau}+\tau_{i}: \nabla \bar{V}_{i}-\nabla \cdot q_{i}+ \\
+\sum_{j=1}^{n}\left(Q_{j i}+\dot{m}_{j i} h_{j i}-\dot{m}_{i j} h_{i j}\right)+\alpha_{i} E_{i}(T)+S_{i},
\end{gathered}
$$

де (:) - оператор подвійного скалярного добутку; $h_{i}=\int_{T_{r e f}}^{T} c_{p(i)} d T-$ масова ентальпія фази $i$, Дж/кг; $c_{p(i)}$ — масова ізобарна теплоємність, Дж/(кг·К); $T_{r e f}$ температура відліку, $\mathrm{K} ; q_{i}=-\alpha_{i}\left[\lambda_{i} \mathrm{c}_{\mathrm{p}(i)}+\mu_{\mathrm{t}, i}\right] \nabla h_{i}(T)$ - вектор густини теплового 
потоку фази $i$ (або фізичне рівняння стану середовища, що зв'язує $q$ з $\nabla T$ ), в якому враховується передача теплоти за рахунок турбулентності потоку, $\mathrm{BT} / \mathrm{m}^{2} ; \lambda_{i}$ - теплопровідність фази $i, \mathrm{Bт} /(\mathrm{м} \cdot \mathrm{K}) ; Q_{j i}=-Q_{i j}-$ інтенсивність теплообміну між фазами $j$ і $i$ (причому $\left.Q_{i i}=0\right), \mathrm{BT} / \mathrm{M}^{3} ; h_{j i}=\left\{\begin{array}{l}h_{j} \text { при } \dot{m}_{j i}>0 \\ h_{i} \text { при } \dot{m}_{j i}<0\end{array}-\right.$ ентальпія на міжфазній поверхні (при випаровуванні це може бути ентальпія пари при температурі крапель води), Дж/кг; $S_{i}-$ об’ємне джерело теплоти від хімічних реакцій, Вт/м ${ }^{3} ; E_{i}(T)=\int_{v=0}^{\infty} K_{v i}\left(\int_{\Omega=4 \pi} I_{v i} d \Omega-4 \pi n_{v i}^{2} I_{0 v i}\left(T_{i}\right)\right) d v-$ об’ємна густина радіаційного теплового потоку селективного випромінювального та поглинального середовища $i$-ї фази, Вт $/ \mathrm{m}^{3} ; v-$ частота випромінювання, Гц; $K_{v i}$ і $n_{v i}-$ селективний коефіцієнт поглинання $\left(\mathrm{M}^{-1}\right)$ і показник заломлення $i$-ї фази відповідно; $\Omega$ - тілесний кут, $\mathrm{cp} ; I_{0 v i}-$ функція Планка, Вт.с/(м².cp);

Спектральну інтенсивність випромінювання $i-1$ фази $\left(\right.$ Вт.с/(м².cp)) $I_{v i}$ для напрямку $s$ у тілесному куті $d \Omega$ можна представити у вигляді залежності:

$$
I_{v i}(s)=I_{v i}\left(s_{0}\right) \exp \left(-\int_{s 0}^{s} K_{v i} d s\right)+\int_{s 0}^{s} n_{v i}^{2} I_{0 v i} K_{v i} \exp \left(-\int_{s^{\prime}}^{s} K_{v i} d s^{\prime \prime}\right) d s^{\prime},
$$

де $s_{0}$ - відповідає границі середовища.

Для твердих конструкційних елементів печі і тістових заготовок, що переміщуються разом із колисковим конвеєром, система рівнянь (1)-(5) спрощується до рівняння теплопровідності виду:

$$
\begin{gathered}
\frac{\partial \rho h}{\partial \tau}=\nabla \cdot[\lambda(T) \nabla T(X)]+ \\
+q_{v}, X_{\text {mov }}(x, y, z, \tau) \cup X_{\text {immov }}(x, y, z) \in X(x, y, z) \in \Omega,
\end{gathered}
$$

де $q_{v}$ - об'ємне джерело теплоти, пов'язане із завантаженням ТЗ і розвантаженням випеченого хліба (BX) 3 печі, $\mathrm{BT} / \mathrm{m}^{3}$, питома потужність якого визначається із системи рівнянь:

$$
q_{v}=\left\{\begin{array}{c}
\dot{m}_{T 3} \frac{\int_{0}^{T_{T 3}} c_{p(T 3)}(T) d T}{V_{T 3}} \\
-\dot{m}_{B X} \frac{\int_{0}^{T_{B X}} c_{p(B X)}(T) d T}{V_{B X}}
\end{array},\right.
$$

де $\dot{m}_{T 3}, \dot{m}_{B X}-$ масова витрата ТЗ/ВX у завантажувально-розвантажувальному вузлі, відповідно, кг/с; $c_{p(T 3)}, c_{p(B X)}$ - масова теплоємність Т3/BX 
відповідно, Дж/(кг·К); $V_{T 3}, V_{B X}-$ об'єм ТЗ/ВХ відповідно, м³ $; X(x, y, z)-$ декартова система координат твердих елементів печі, що включає нерухому $X_{\text {im mov }}(x, y, z)$ та рухому частини, яка відноситься до колискового конвеєра $\mathrm{i}$ тістових заготовок, $X_{\text {im mov }}(x, y, z, \tau)$; $V_{\text {conv }}$ - вектор швидкості переміщення конвеєра разом із хлібом, що випікається, м/с; $\Omega$ - розрахункова область пекарської печі.

Коефіцієнт обміну кількістю руху між фазами у рівняннях (2)-(5) залежить від обраної моделі гідравлічного опору, числа Рейнольдса, в'язкості тощо і визначається залежно від фізичного стану фаз, що взаємодіють: рідина-рідина або рідина-газ, або газ-газ. Так, наприклад, коефіцієнт обміну кількістю руху між краплями води $p$ і газом $g$ можна визначити як [4]:

$$
K_{p g}=\frac{\alpha_{g} \alpha_{p} \rho_{p} f}{\tau_{p}}
$$

де $\tau_{p}=\frac{\rho_{p} d_{p}^{2}}{18 \mu_{\text {eff }}}-$ час релаксації крапель води, c; $d_{p}$ - діаметр крапель води, м; $\mu_{e f f}=\mu_{g} /\left(1-\alpha_{p}\right)^{2,5}-$ ефективна динамічна в'язкість газ-краплі рідини, Па.c; $\mathrm{f}=C_{D} \mathrm{Re} / 24-$ функція гідравлічного опору; $C_{D}$ - коефіцієнт гідравлічного опору.

Число Рейнольдса двофазового середовища визначається співвідношенням:

$$
\operatorname{Re}=\frac{\rho_{p}\left|\bar{V}_{p}-\bar{V}_{g}\right| d_{p}}{\mu_{\text {eff }}} .
$$

Коефіцієнт гідравлічного опору визначається залежно від числа Рейнольдса:

$$
C_{D}=\left\{\begin{array}{c}
\frac{24}{\operatorname{Re}} \text { при } \operatorname{Re}<1 ; \\
\frac{24}{\operatorname{Re}}\left(1+0,1 \mathrm{Re}^{\frac{3}{4}}\right) \text { при } 1 \leq \operatorname{Re} \leq 1000 ; \\
\frac{2}{3} \frac{d_{p}}{\lambda_{R T}}\left[\frac{1+17,67\left(f^{*}\right)^{\frac{6}{7}}}{18,67 f^{*}}\right]^{2} \text { при } \operatorname{Re}>1000,
\end{array}\right.
$$

де $f^{*}=\left(1-\alpha_{p}\right)^{3} ; \lambda_{R T}=\left(\sigma /\left(\mathrm{g} \Delta \rho_{p g}\right)\right)^{0,5}$ - довжина хвилі нестабільності РоліТейлора, м; $\sigma-$ коефіцієнт поверхневого натягу, Н/м; g - прискорення вільного падіння, м/ $\mathrm{c}^{2} ; \Delta \rho_{p g}$ - різниця густини між фазами $p$ i $g, \kappa г / \mathrm{m}^{3}$.

Початкові умови для системи рівнянь (1)-(6) при $\tau=0$ : 


$$
\left\{\begin{array}{l}
\bar{V}_{i}=0 ; \quad p_{i}=0 ; \quad T_{i}=T_{i}^{0} ; \\
k_{i}=k_{i}^{0} ; \quad \varepsilon_{i}=\varepsilon_{i}^{0} ; \\
L_{p}=L^{0} ; \quad \alpha_{p}=\alpha^{0},
\end{array}\right.
$$

де $i=\overline{1, n}$ - індекс фази в потоці; $T_{i}^{0}, k_{i}^{0}, \varepsilon_{i}^{0}$ - початкова температура (К), масова турбулентна кінетична енергія (Дж/кг) і швидкість іï дисипації (Дж/(кг·c)), масова $L^{0}-$ початкова довжина зони водяної пари в газових каналах хлібопекарської печі, м; $\alpha^{0}-$ об'ємна частка водяної пари разом із краплями довжиною $L^{0}$.

Граничні умови для системи рівнянь (1)-(8) при $\tau>0$ :

- у вхідних перетинах печі задаються параметри для грійних газів $(i=g)$ і водяної пари $(i=p)$, масової витрати і температури Т3:

$$
\left\{\begin{array}{l}
n \cdot \bar{V}_{i}=V_{i}^{i n} ; T_{i}=T_{i}^{i n} ; \dot{m}_{T 3}=\dot{m}_{T 3}^{i n} ; T_{T 3}=T_{T 3}^{i n} ; \\
k_{i}=k_{i}^{i n} ; \varepsilon_{i}=\varepsilon_{i}^{i n} ; \quad \alpha_{i}=\alpha_{i}^{i n},
\end{array}\right.
$$

де $n$ - вектор зовнішньої нормалі до поверхонь вхідних січень печі; $V_{i}^{i n}, T_{i}^{\text {in }}$, $\dot{m}_{T 3}^{i n}, T_{T 3}^{i n}, k_{i}^{i n}, \varepsilon_{i}^{i n}, \alpha_{i}^{i n}-$ нормальна швидкість (м/с), температура газових фаз (К), масова витрата Т3 (кг/c), температура Т3 (К), масова турбулентна кінетична енергія (Дж/кг) та швидкість іiї дисипації (Дж/(кг·с)), об’ємна часка $i$-ї фази на вході у піч;

- у відхідних перетинах печі задаються параметри для суміші (14), газових фаз і масової витрати і температури випеченого хліба (15)

$$
\begin{gathered}
p_{\text {mix }}=0, \\
\left\{\begin{array}{l}
T_{i}=T_{i}^{\text {out }} ; \alpha_{i}=\alpha_{i}^{\text {out }} ; \dot{m}_{\mathrm{BX}}=\dot{m}_{\mathrm{BX}}^{\text {out }} ; T_{\mathrm{BX}}=T_{\mathrm{BX}}^{\text {out }} ; \\
k_{i}=k_{i}^{\text {out }} ; \varepsilon_{i}=\varepsilon_{i}^{\text {out }},
\end{array}\right.
\end{gathered}
$$

де $p_{\text {mix }}$ - надлишковий тиск суміші газів, Па; $T_{i}^{\text {out }}, \alpha_{i}^{\text {out }}, \dot{m}_{B X}^{\text {out }}, T_{B X}^{\text {out }}, k_{i}^{\text {out }}, \varepsilon_{i}^{\text {out }}-$ температура (К), об'ємна частка $i$-ї фази, масова витрата ВX (кг/с), температура ВX (К), масова турбулентна кінетична енергія (Дж/кг) і швидкість іiі дисипації (Дж/(кг·с));

- на границі контакту між твердими тілами задаються умові абсолютного контакту:

$$
\left\{\begin{array}{l}
\{T\}=0 \\
\{n \cdot q\}=0,
\end{array}\right.
$$

де $\{T\}=T^{+}-T ; \quad\{n \cdot q\}=n^{+} \cdot q^{+}-n^{-} \cdot q^{-} ;$«+» і «-» означає ліворуч $\mathrm{i}$ праворуч від границі контакту; $q=-\lambda(\mathrm{T}) \nabla \mathrm{T}-$ вектор густини теплового потоку; $n$ - вектор зовнішньої нормалі до поверхні тіла; 
- на границі контакту між багатофазним середовищем печі, Т3 і огородженням газових каналів задаються умови прилипання для кожної із газових фаз та умови спряження по температурі та густині теплового потоку:

$$
\left\{\begin{array}{c}
\bar{V}_{i}=0 ; \\
\{T\}=0 ; \\
\sum_{i=1}^{n}\left[n \cdot\left(-\alpha_{i} \lambda_{i}\left(T_{i}\right) \nabla T_{i}\right)-n \cdot q_{r i}\right]-q_{l h}=n \cdot\left(-\lambda_{\text {eff }}(T) \nabla T\right),
\end{array}\right.
$$

де $n$ - кількість фаз в потоці; $q_{r i}=\alpha_{i} \int_{v=0}^{\infty}\left[n_{v i}^{2} \varepsilon_{v} I_{0 v i}-\varepsilon_{v} \int_{s \cdot n>0} I_{i n, v i}(s \cdot n) d \Omega\right] d v-$ результуючий радіаційний потік $i$-ї фази, Вт/м²; $\varepsilon_{v}-$ спектральний ступінь чорноти поверхні газових каналів печі; $q_{l h}=\frac{h_{l h}\left(\dot{m}_{\text {cond }}\left(\bar{T}_{F}\right)-\dot{m}_{\text {evap }}\left(\bar{T}_{F}\right)\right)}{F_{\text {тз(BX) }}}-$ поверхнева густина теплового потоку, пов'язана 3 масообміном на поверхні T3 (вологообміном завдяки конденсаціï/ випаровування вологи), Вт/м ${ }^{2} ; h_{l h}$ теплота фазового переходу 1-го роду для води (конденсація/випаровування), Дж/кг; $\dot{m}_{\text {cond }}, \dot{m}_{\text {evap }}$ - масова витрата вологи при конденсації і випаровуванні, відповідно, кг/с; $\bar{T}_{F}$ - середня інтегральна температура поверхні Т3/ВХ, К; $F_{\mathrm{T} 3(\mathrm{BX})}$ - площа поверхні Т3/ВХ, м²; $\lambda_{\text {eff }}$ - ефективна теплопровідність Т3/ВX, Вт/(м·К);

- на границі контакту огороджень печі з оточуючим повітрям задаються граничні умови конвективного типу:

$$
n \cdot[-\lambda(T) \nabla T]=\alpha(T)\left(T-T_{p}\right),
$$

де $\alpha$ - коефіцієнт тепловіддачі; $T_{\mathrm{p}}$ — температура оточуючого середовища.

\section{Висновки}

Розроблена математична модель процесу випікання хліба в газових каналах пекарної камери з урахуванням радіаційно-конвективного теплообміну, масообміну з урахуванням введення водяної пари для зволожування тістових заготовок і турбулентності багатофазного потоку.

Модель дає змогу 3 достатньою точністю і детальністю враховувати всі режимні та конструктивні особливості сучасних конвеєрних хлібопекарських печей і проводити широкі параметричні дослідження сполученого теплообміну в них з виходом на кінцевий показник - якість готових виробів.

\section{Література}

1. Vanin F. Crust formation and its role during bread baking / F. Vanin, T. Lucas, G. Trystram // Trends in Food Science \& Technology. — 2009. — \#20. — P. 333 - 343.

2. Purlis E. Modelling the browning of bread during baking / E. Purlis, V. Salvadori // Food Research International. — 2009. — \# 42. — P. 865-870. 
3. Purlis E. Browning development in bakery products- A review. - Journal of Food Engineering. - 2010. — \# 99. - P. 239-249.

4. Lostie M. Study of sponge cake batter baking process.II. Modeling and parameter estimation / M. Lostie, R. Peczalski, J. Andrieu, M. Laurent // Journal of Food Engineering, — 2002. \# 55. - P. 349-357.

4. Bikard J. Simulation of bread makingprocess using a direct 3D numerical method at microscale: Analysis of foaming phase during proofing. / J. Bikard, T. Coupez, G. Valle, B. Vergnes // Journal of Food Engineering. — 2008. — \# 85. - P. 259-267.

5. Broyart $B$. Modelling of heat and mass transfer phenomena and quality changes during continuous biscuit baking using both deductive and inductive (neural network) modelling principles / B. Broyart, G. Trystram // Food and Bioproducts Processing. — 2003. — \# 81. P. $316-326$.

6. Bikard J. Simulation of bread making process using a direct 3D numerical method at microscale: Analysis of baking step. // Int J Mater Form. — 2012. — \# 5. — P. 11-24.

7. Baldino N. Modeling of baking behavior of semi-sweet short dough biscuits / N. Baldino, D. Gabriele, F. Lupi, B. de Cindio, L. Cicerelli // Innovative Food Science and Emerging Technologies. - 2014. - \# 25. - P. 40-52.

8. Десик М.Г. Математичне моделювання прогріву тістової заготовки циліндричної форми / М.Г. Десик, Ю.С. Теличкун, І.М. Литовченко, В.І. Теличкун // Наукові праці Національного університету харчових технологій. — 2016. - Т. 22, № 4. - С. 134-140.

9. Cornejo P. Mathematical Modeling of Coal Gasification in Fluidized Bed Reactor Using an Eulerian Granular Description / P Cornejo, O. Farias // Intern. J. of Chem. Reactor Eng. 2011. - Vol. 9(1). - P. 1515-1542.

10. Моделирование графитирования нефтяного кокса в шахтной электропечи непрерывного действия / Е.Н. Панов, А.Я. Карвацкий, С.В. Кутузов [и др.] // Весник НТУУ «КПИ». Химическая инженерия, экология и ресурсосбережение. — 2011. — № 1(7). — С. 48-52. 